\title{
Plant growth promotion of barley (Hordeum vulgare L.) by potassium solubilizing bacteria with multifarious plant growth promoting attributes
}

\author{
Tanvir Kaur ${ }^{1}$, Rubee Devi ${ }^{1}$, Divjot Kour ${ }^{1}$, Ashok Yadav ${ }^{2}$ \& Ajar Nath Yadav ${ }^{1^{\star}}$ \\ ${ }^{1}$ Microbial Biotechnology Lab, Department of Biotechnology, Dr. KS Gill Akal College of Agriculture, Eternal University, Himachal Pradesh, India \\ ${ }^{2}$ Department of Botany, Institute of Science, Banaras Hindu University, Uttar Pradesh, India \\ ^Email: ajar@eternaluniversity.edu,in; ajarbiotech@gmail.com
}

\section{OPEN ACCESS}

\section{ARTICLE HISTORY}

Received: 09 July 2021

Accepted: 03 October 2021

Available online

Version 1.0: 31 December 2021

\section{Check for updates}

\section{Additional information}

Peer review: Publisher thanks Sectional Editor and the other anonymous reviewers for their contribution to the peer review of this work.

Reprints \& permissions information is available at https://horizonepublishing.com/ journals/index.php/PST/open_access_policy

Publisher's Note: Horizon e-Publishing Group remains neutral with regard to jurisdictional claims in published maps and institutional affiliations.

Indexing: Plant Science Today, published by Horizon e-Publishing Group, is covered by Scopus, Web of Science, BIOSIS Previews, Clarivate Analytics, etc. See https:// horizonepublishing.com/journals/index.php/ PST/indexing_abstracting

Copyright: ( $\subset$ The Author(s). This is an openaccess article distributed under the terms of the Creative Commons Attribution License, which permits unrestricted use, distribution and reproduction in any medium, provided the original author and source are credited (https://creativecommons.org/licenses/ by/4.0/)

\section{CITE THIS ARTICLE}

Kaur T, Devi R, Kour D, Yadav A, Yadav AN. Plant growth promotion of barley (Hordeum vulgare L.) by potassium solubilizing bacteria with multifarious plant growth promoting attributes. Plant Science Today. 2021;8 (sp1):17-24. https://doi.org/10.14719/pst.1377

\begin{abstract}
Potassium (K) is the foremost macronutrients for growth of plant, soil health and fertility. The huge application of NPK chemical fertilizers negatively impacts the economy and is a threat to environmental sustainability. The rapid depletion of $\mathrm{K}$ mineral in soil is due to the application of agrochemicals agricultural fields for the production of crops in India. In present investigation, $\mathrm{K}$-solubilizing microbes (KSM) were isolated and enumerated from cereal crops growing in Sirmour Himachal Pradesh. A total 125 bacteria were isolated and screened for $\mathrm{K}$ - solubilization on Aleksandrov agar plates and found that 31 bacterial strains exhibited K-solubilization. These $31 \mathrm{~K}$-solubilizing strains of bacteria were additionally screened for other plant growth promoting (PGP) potential including solubilization of minerals, production of siderophores, ammonia, hydrogen cyanide and indole acetic acids. The performance of an efficient K-solubilizer was evaluated for plant growth promoting ability in pot assay under in vitro conditions. The strain EU-LWNA-25 positively influenced shoot length, fresh weight, carotenoids and total sugar content than the full dose, half dose and control. The strain enhancing physiological and growth parameters was identified by BLASTn analysis as Pseudomonas gessardii EU-LWNA-25. K-solubilizing plant growth promoting bacteria could be suitable bioinoculants for Rabi seasonal crops and overcomes the challenges of sustainable agriculture in $\mathrm{K}$-deficient soil.
\end{abstract}

\section{Keywords}

Biodiversity, Bio-inoculants, PGP attributes, Potassium solubilization, Sustainable agriculture

\section{Introduction}

Potassium (K), the $7^{\text {th }}$ most abundant, is one of the vital nutrients which is requisite in large quantity for functioning of cells by all living organisms. It plays a major role in activation and production of enzymes that are involved in regulating the photosynthesis rate i.e. adenosine triphosphate and transportation of water and nutrients throughout the plant. The deficient supply of potassium in plants depressed the translocation of amino acids, calcium (Ca), magnesium (Mg), nitrates, and phosphates. In soil, the nutrient is present in different insoluble forms, majorly fixed forms which cannot be absorbed by plant systems $(1,2)$. To fulfill the plant nutrient requirement, potassium fertilizer is being used on a huge level around the globe. The use of fertilizer also has a harmful impact on the environment and it is necessary to have a substitute indigenous source of potassium that produces crops in 
a sustainable way. The community of phytomicrobiomes and soil microbiomes has an ability to influence the fertility of soil through mineralization and nutrient release $(3,4)$.

Implification of efficient potassium solubilizing microbes is one of the possibilities for the improvement of fertility and health of soil as well as agricultural sustainability. Efficient potassium solubilizing bacteria (KSB) secretes wide variety of enzymes and organic acids that act on insoluble form of potassium and convert it into solubilized form which is available to plant. The potassium solubilizing bacteria also produces amino acids, vitamins which helps in growth promotion. One possible way to alleviate deficiency of potassium is to use of a KSB that play major roles in availing the potassium minerals by $\mathrm{K}$ solubilization through diverse mechanisms like acidolysis, chelation, complexolysis, exchange reactions and organic acids production $(5,6)$. These microbes residing in the rhizospheric region of plants are known as K-solubilizers and have the capability to augment potassium availability to plants.

Interactions between microbes and plants occur through associative, endophytic or symbiotic processes with the distinct degree of proximity with the surrounding soil and the roots. PGP soil and rhizospheric bacteria associated with plants have capability to promote growth of plant, enhance crop yield and soil fertility (7). The huge number of PGP microbial strains which are commercially used as the adjuncts to agricultural practice, including Agrobacterium, Azotobacter, Azospirillum, Burkholderia, Bacillus, Pseudomonas, Paenibacillus, Streptomyces and Serratia (8). The most significant PGP microbes are Acidithiobacillus ferrooxidans, Azospirillum, Azotobacter, Burkholderia, Bacillus edaphicus, B. circulans, B. mucilaginosus, $B$. subtilis, Paenibacillus sp. and Pseudomonas. Plant growth promoting microbes play an important role in planting using different plant growth promoting mechanisms of solubilization of micronutrient, biological nitrogen fixation, production of siderophores and plant growth regulators.

Potassium solubilizing PGP attributes has been reported by worldwide researchers and several microbial strains belongs to different genera, such as Acidothiobacillus, Bacillus, Burkholderia and Pseudomonas, which have capability to mineralize potassium inaccessible form from $\mathrm{K}$-bearing minerals in soil (9-13). The potassium solubilizing fungi (KSF) strains namely, Apergillus niger and A. terreus sorted out from potassium rich soil samples are observed to increase fertility of soil (14-16). Moreover, KSB have ability to mineralize rock potassium, such as illite, micas and ortho classes (feldspar), also through excretion and chelate production of silicon ions or organic acids to bring the potassium into solution (17). Certain groups of microorganisms are well recognized to solubilize potassic minerals into soluble form which could be utilized by the plants (18).

In general, PGP microbes assist the growth of plants by direct or indirect mechanism of action. The direct mechanism promotes plant growth either by supplying nutrients (N, P, Fe, and Zn) or regulating the levels of phytohormones like auxin, cytokinin, gibberellins and ethylene), whereas indirect action mechanisms decreases the various pathogens and its deleterious effects. Now various microbial species like potassium solubilizing microorganisms (KSM) are widely used as a worthy substitute of chemically synthesized fertilizer. The present investigation deals with study of potassium solubilizing bacteria (KSB) sorted out from Baru Sahib, Himachal Pradesh and their role in promotion of plant growth.

\section{Materials and Methods}

\section{Sample sites and sampling}

The sample were collected from Valley of Divine Peace, Baru Sahib, $30.7537^{\circ} \mathrm{N}, 77.2965^{\circ} \mathrm{E}$, which is located in a remote corner of Sirmour district, Himachal Pradesh, India. The soil samples were collected from crops such as Amaranthus, barley, buckwheat, finger millet, foxtail millet, maize, oats, pearl millet and wheat growing at Baru Sahib in sterile labeled polythene bags and processes immediately.

\section{Isolation and enumeration of microbes}

The plant allied rhizospheric microbes were sorted out and enumerated using different culture media such as nutrient agar, trypticase soya agar, soil extract agar, King's B agar, rose Bengal agar and potato dextrose agar. The culturable microbes were sorted out from root associated soil through enrichment technique. Once the microbes were isolated, the colonies were purified on respective growth media and obtained single distinct colonies of bacteria were preserved for future use.

\section{Screening of bacteria for PGP traits}

All obtained microbial isolates were screened for $\mathrm{K}$ solubilization on modified Aleksandrov agar media supplemented with insoluble K-alumina silicate as per the standard method of $\mathrm{Hu}$, Chen (19). The selected K-solubilizers isolates were screened for other PGP attributes such as phosphorus solubilization on Pikovskaya agar medium using three various insoluble phosphorus sources i.e. apatite, rock phosphate and tricalcium phosphate (20), zinc solubilization on nutrient agar supplemented with $1 \%$ each of zinc phosphate, zinc oxide and zinc sulphide (21), siderophores production on chrome azurol-S agar, indole acetic acid (IAA), ammonia and hydrogen cyanide (HCN) according to standard method of (22)

\section{Identification of selected KSB and phylogenetic analysis}

Genomic DNA of efficient K-solubilizers was extracted by the modified method of as described (23). The 16S rRNA gene of isolated DNA samples was amplified using set primers $\mathrm{pA}$ and $\mathrm{pH}$ to obtain approximately 1500-bp fragment. The PCR amplification was carried out as described earlier (23). The amplified PCR products of selective isolates were purified with a QIA quick purification kit (Qiagen). The identity of bacteria was determined by similarity percentage (>97\%) available at the GenBank database using BLASTn. The phylogenetic tree was constructed 
to know the taxonomical affiliation of bacteria using neighbor joining (NJ) method in the program MEGA 4.0.2. (24).

\section{Evaluation of selected KSM for plant growth promotion}

A pot experiment was designed to evaluate the effect of the potential and efficient potassium solubilizing bacterial strains on growth of barley in glass house in non-sterile soil. LW-NA-25 was inoculated in culture media and incubated at $30{ }^{\circ} \mathrm{C}$ for $24 \mathrm{hr}$ in incubator shaker. Bacterized seed of barley were sown in plastic pots $(30 \mathrm{~cm} \times 30 \mathrm{~cm} \times 26 \mathrm{~cm})$ containing $4 \mathrm{~kg}$ unsterile soil. The pots were watered according to the need.

\section{Determination of growth and physiological parameters}

Various growth parameters were assayed including root/ shoot lengths and fresh/dry weight. The content of chlorophyll and carotenoid was determined by the method of Lichtenthaler (25). In $80 \%$ acetone fresh leaves of barley were homogenized and OD was taken at respective wavelength and the concentration of total chlorophyll and carotenoids in leaf was calculated through the following equation.

$$
\begin{aligned}
& \text { Chla }\left(\mathrm{mg} \mathrm{g}^{-1} \mathrm{FW}\right)=12.25 \mathrm{~A}_{663}-2.79 \mathrm{~A}_{645} \\
& \operatorname{Chlb}\left(\mathrm{mg} \mathrm{g}^{-1} \mathrm{FW}\right)=21.50 \mathrm{~A}_{645}-5.10 \mathrm{~A}_{663} \\
& \text { Chla }+b=7.15 \mathrm{~A}_{663}+18.71 \mathrm{~A}_{645} \\
& C_{x+c}=\frac{1000 A_{470}-1.82 \mathrm{Chla}-85.02 \mathrm{Chlb}}{198}
\end{aligned}
$$

Total soluble sugar (TSS) content of barley was determined by the standard method (26). Fresh leaves of barley were crushed in the 95\% ethyl alcohol and alcoholic extract was reacted with freshly prepared anthrone reagent. The extract was incubated at $100{ }^{\circ} \mathrm{C}$ for $10 \mathrm{~min}$ and absorbance was determined at $625 \mathrm{~nm}$. The concentration of TSS was calculated using the standard curve of glucose and expressed in $\mu \mathrm{g} / \mathrm{g}$ FW. Leaf phenolics and flavonoid contents were determined.

\section{Results}

\section{Isolation, screening and identification of bacteria}

A total of 125 bacterial strains were sorted out from several cereal crops grown in the Baru Sahib, Himachal Pradesh and maintained. Noteworthy variations were observed among bacterial population in each sample on various growth media (Table 1). CFU ranges from $0.02-2.69 \times 10^{7}$ in different growth media. Among the media used, nutrient agar supported highest diversity followed by King's B agar from maize and Amaranthus respectively. Among 125 bacterial strains, 31 bacterial strains were found to be exhibiting the K-solubilizing attributes on insoluble K-alumina silicate. All K-solubilizing isolates were further screened for other PGP attributes and found $61 \%$ and $35 \%$ as $\mathrm{P}$ and $\mathrm{Zn}$ solubilizer respectively, whereas $74 \%$ produced siderophores, $61 \%$ ammonia and $58 \%$ produced $\mathrm{HCN}$ and IAA (Table 2). The selected K-solubilizing strain EU-LWNA-25

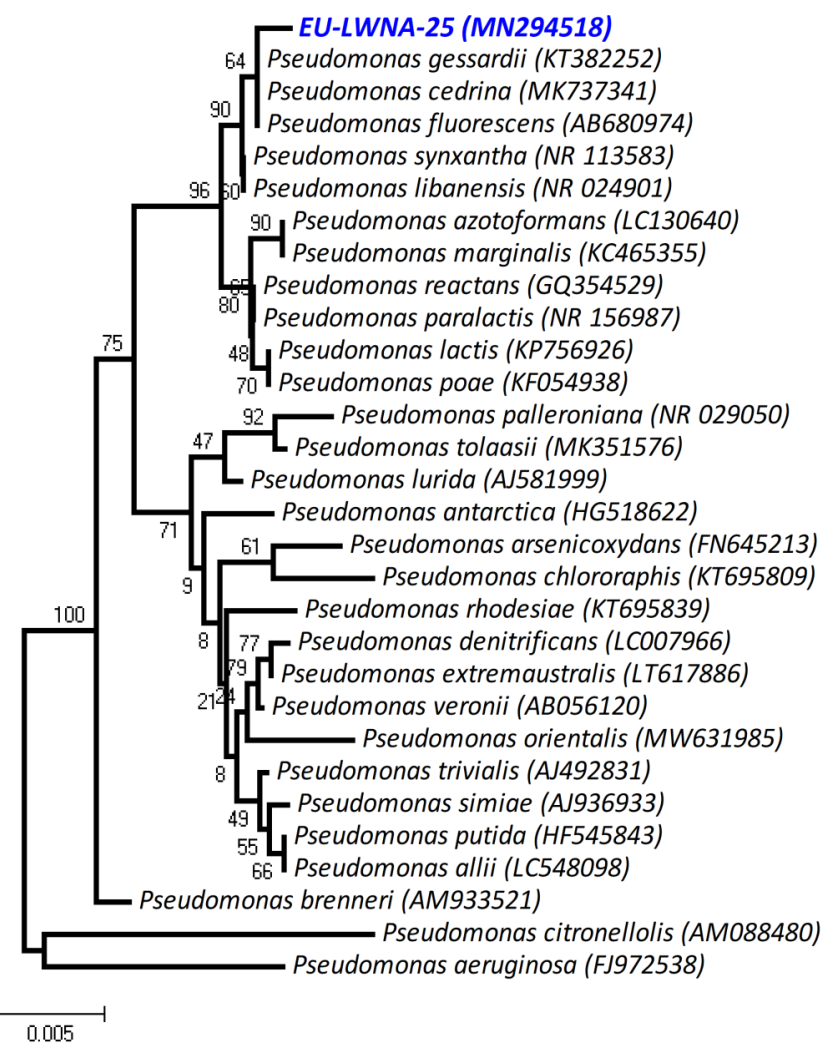

Fig. 1. Phylogenetic tree showing the relationship among 07 potassium solubilizing bacterial isolates, 16S rRNA gene sequences with reference sequences obtained through BLAST analysis. The trees were constructed using Neighbor joining with algorithm using MEGA 4 software (45).

showed 99\% similarity to Pseudomonas gessardii whose phylogenetic tree was constructed using available databases.

\section{Evaluation of selected KSM for plant growth promotion}

The selected K-solubilizer namely, P. gessardii EU-LWNA-25 was used for evaluating PGP of barley crop by pot assay under in vitro conditions (Fig. 1).

\section{Determination of growth and physiological parameters}

K-solubilizer, $P$. gessardii EU-LWNA-25 increases the growth parameter shoot length, root length and fresh weight (Fig. 2 and 3). The increase in shoot length was 2.2, 1.4 and 1.3 folds higher as compare to full dose, half of chemical fertilizer and untreated control respectively. The root length of EU-LWNA-25 treated plant was 1.1 fold higher as compare to control, but as compare to full and half dose of fertilizer was lower. EU-LWNA-25 significantly increases $1.4,1.9$ and 1.4 folds higher fresh weight of the plant in comparison with control, half and full dose of chemical fertilizer. The dry weight of EULWNA-25 treated plant was 1.6 fold higher as compare to chemical fertilizer both full and half dose. The chlorophyll content of EU-LWNA-25 treated plant was 1.9 and 1.5 fold higher in comparison with half dose of potassium fertilizer dose and untreated control plant, respectively (Fig. 4a). The content of carotenoids significantly 1.5, 3.0 and 2.7 fold higher as compare to potassium chemical full dose, half dose and untreated control respectively (Fig. 4b). The sugar content was 1.1 and 1.3 fold higher in plant treated with EU-LWNA-25 as compare to full and half dose of chemical fertilizer (Fig. 4c). The EU-LWNA-25 doesn't increase phenolics con- 
Table 1. Total viable count of rhizospheric microbes from different cereals and pseudo cereals growing in Divine Valley of Baru Sahib

\begin{tabular}{|c|c|c|c|c|c|c|}
\hline \multirow{2}{*}{ Samples } & \multicolumn{6}{|c|}{ CFU per $\mathrm{g}$ of soil on different media $\left(\times 10^{7}\right)$} \\
\hline & NA & KB & TSA & $\mathbf{T}_{3} \mathbf{A}$ & LB & RBA \\
\hline Amaranthus & 1.06 & 1.95 & 0.95 & 0.43 & 0.57 & 0.02 \\
\hline Barley & 0.55 & 0.65 & 1.25 & 0.25 & 0.55 & 0.12 \\
\hline Buckwheat & 0.63 & 0.77 & 1.03 & 0.28 & 0.70 & 0.05 \\
\hline Fox tail millet & 0.76 & 0.60 & 0.60 & 0.46 & 1.20 & 0.04 \\
\hline Maize & 2.69 & 2.25 & 1.95 & 0.70 & 1.07 & 0.15 \\
\hline Oats & 0.45 & 0.85 & 1.11 & 0.12 & 0.58 & 0.15 \\
\hline Pearl millet & 0.73 & 1.46 & 0.65 & 0.22 & 1.07 & 0.04 \\
\hline Wheat & 0.65 & 1.25 & 1.30 & 0.14 & 0.45 & 0.18 \\
\hline
\end{tabular}

NA-Nutrient agar, KB-King's B agar, TSA-Tryptic soy agar, MDM-Modified Dobereiner medium, LB-Luria Bertani media, RBA-Rose Bengal agar, JA-Jensen Agar

Table 2. Plant growth promotion attributes of K-solubilizing bacteria

\begin{tabular}{|c|c|c|c|c|c|c|}
\hline K-solubilizers & $\mathbf{P}$ & Zn & Sid & HCN & $\mathbf{N H}_{3}$ & IAA \\
\hline EU-A1SJ1 & + & + & - & + & + & + \\
\hline EU-A1SN1 & + & - & + & - & + & + \\
\hline EU-A1SNL1 & + & - & + & + & - & + \\
\hline EU-A2RJ1 & + & - & + & + & + & + \\
\hline EU-A2RK2 & + & - & + & - & - & - \\
\hline EU-A2RT3A2 & + & + & - & + & + & + \\
\hline EU-A2SB1 & + & + & - & - & - & - \\
\hline EU-A2SK1 & + & + & + & + & - & + \\
\hline EU-A2SN1 & + & - & - & - & - & - \\
\hline EU-A2SNL2 & + & - & + & - & - & - \\
\hline EU-A2SNL3 & - & + & - & - & - & - \\
\hline EU-A2ST.R1 & + & + & + & - & - & + \\
\hline EU-A3SNL1 & - & - & + & - & - & - \\
\hline EU-B1SB1 & - & + & - & + & + & - \\
\hline EU-B2RK1 & - & - & + & + & + & + \\
\hline EU-B2RK2 & + & - & + & + & + & + \\
\hline EU-B2RN1 & + & - & + & + & + & + \\
\hline EU-B2SNL1 & + & + & + & - & + & + \\
\hline EU-B2ST3.1 & - & - & - & + & + & + \\
\hline EU-B3RT3.1 & + & - & + & - & + & + \\
\hline EU-B3SK2 & + & - & + & - & - & - \\
\hline EU-B3SN2 & - & - & + & + & + & - \\
\hline EU-B3SN4 & - & - & + & + & + & - \\
\hline EU-C1RNL1 & - & - & + & + & + & - \\
\hline EU-C2RK2 & - & - & + & + & + & + \\
\hline EU-C2SN1 & - & - & - & + & + & + \\
\hline EU-LWNA-25* & + & + & + & + & + & + \\
\hline EU-LWNA-38 & + & + & + & + & - & + \\
\hline
\end{tabular}

${ }^{\star}$ Pseudomonas gessardii EU-LWNA-25, P-Phosphate, Zn-Zinc, Sid-Siderophores, HCN-Hydrogen cyanide, $\mathrm{NH}_{3}$-Ammonia, IAA- Indole acetic acid

tent, whereas the culture significantly increased flavo- Discussion

noids content by 1.0, 1.1 and 1.0 fold as compare to full dose, half dose of potassium fertilizer and untreated control respectively (Fig. $4 \mathrm{~d}$ and e).
Over the years, various types of chemically synthesized fertilizers have been applied in the agricultural fields to fulfill 


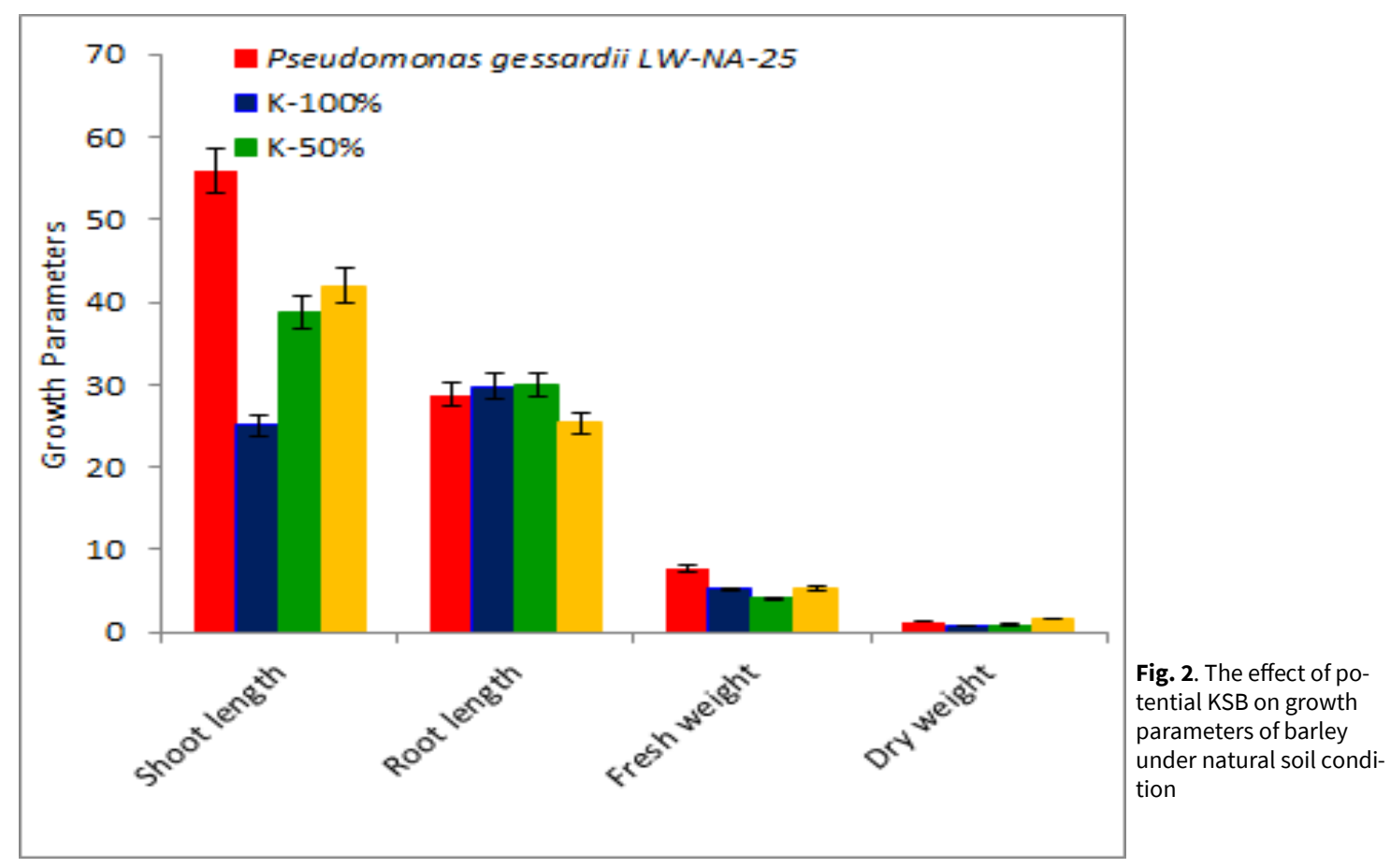

the nutrient requirement of plants and to increase the crop fertilizer of various nutrients have been known and potassiproductivity. Urea, diammonium phosphate and potash as um is one of the nutrients. a source of important macronutrient nitrogen, phosphorus and potassium respectively are the three main chemical fertilizers which were being frequently used from the past

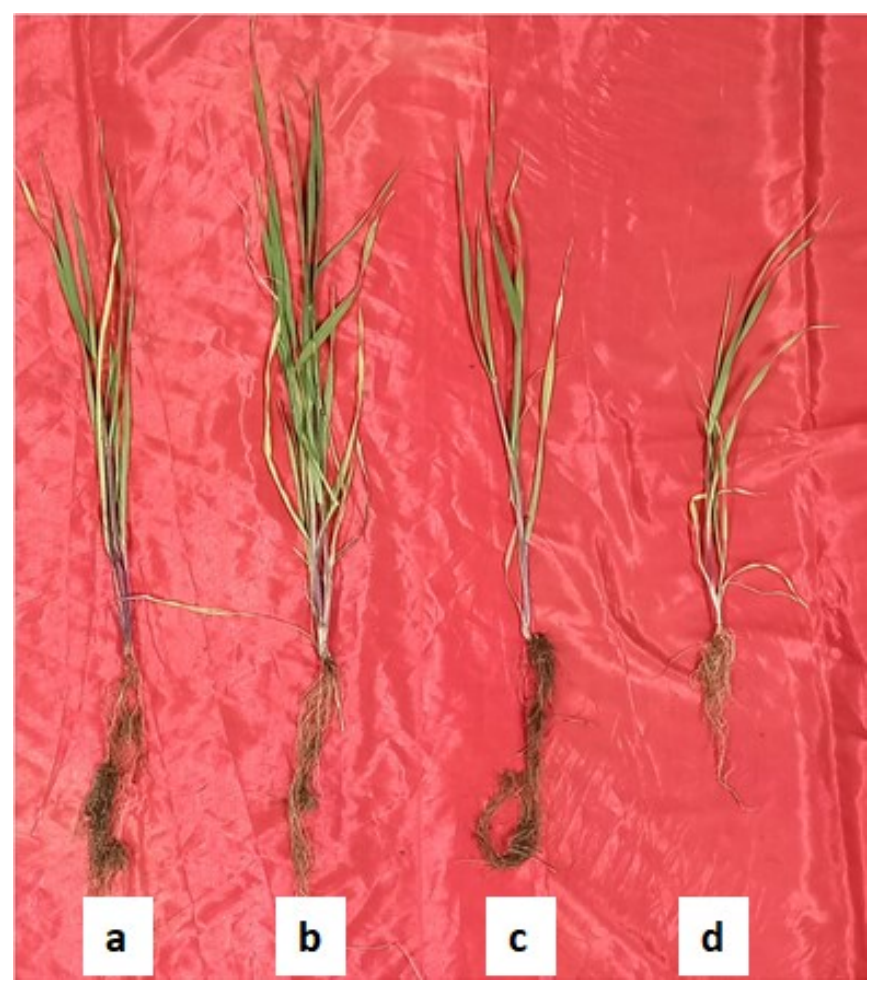

Fig. 3. The effect of KSB on the growth parameters barley (a) Pseudomonas gessardii LW-NA-25 (b) K-100\% (c) K-50\% (d) Control

five decades. The application of chemical based products have conquently affects the quality of the soil. Currently, in many parts of the world, chemically based fertilizers have been known to be accumulate in the soil as a pollutant that leads to the decrease of soil biodiversity as well. Many studies around the globe have been published that have concluded microbes as an alternative fertilizer. Microbial bio-
Potassium is a major micronutrients for plants that influences growth, development and quality of grain. It also plays significant role in uptake and transporatation of nutrients and synthesizes of cells and biomolecules like enzymes, proteins, starch and vitamins. Potassium is also one of the limiting nutrients as the present insoluble form of potassium is cannot be utilized by the plants. The PGPMs use is an effective approach that could replace the use of agro-chemical. There are many reports on the potassium solubilizing microbes possessing other PGP attributes (2730). KSMs play an important role in $\mathrm{K}$ solubilization and mobilization in plants and help in different activities such as metabolism of energy, synthesis of starch, nitrate reduction, photosynthesis and degradation of sugar (31).

In the present study barley inoculated is $P$. gessardii EU-LWNA-25 showed an increase shoot length, root length and fresh weight biomass. Pseudomonas gessardii, a Gramnegative, rod shaped and fluorescent bacterium that significantly proven as efficient enhancer of the plant barley has also been reported earlier as an efficient PGP bacteria under heavy metals stress conditions. In a report, $P$. gessardii was reported for enhancing sunflower growth parameters and lead tolerance ability of plants (32). In another report, this particular bacterium was reported as phosphorus solubilizer (33). Many studies have also confirmed that PGPMs increase the growth parameters. In a report, a promising $\mathrm{K}$ solubilizing bacterium, Paenibacillus glucanolyticus obtained from the rhizospheric region of blackpepper was significantly improved plant growth and K uptake (34). In another report, Bacillus megaterium isolated from Iranian soil was reported as an efficient KSB. This strain has also been reported for enhancing the soluble $K$ content in in vitro condition as compared to control (35).

In a report, Burkholderia cepacia was suggested as potential potassium solubilizing and mobilizing bacteria. 

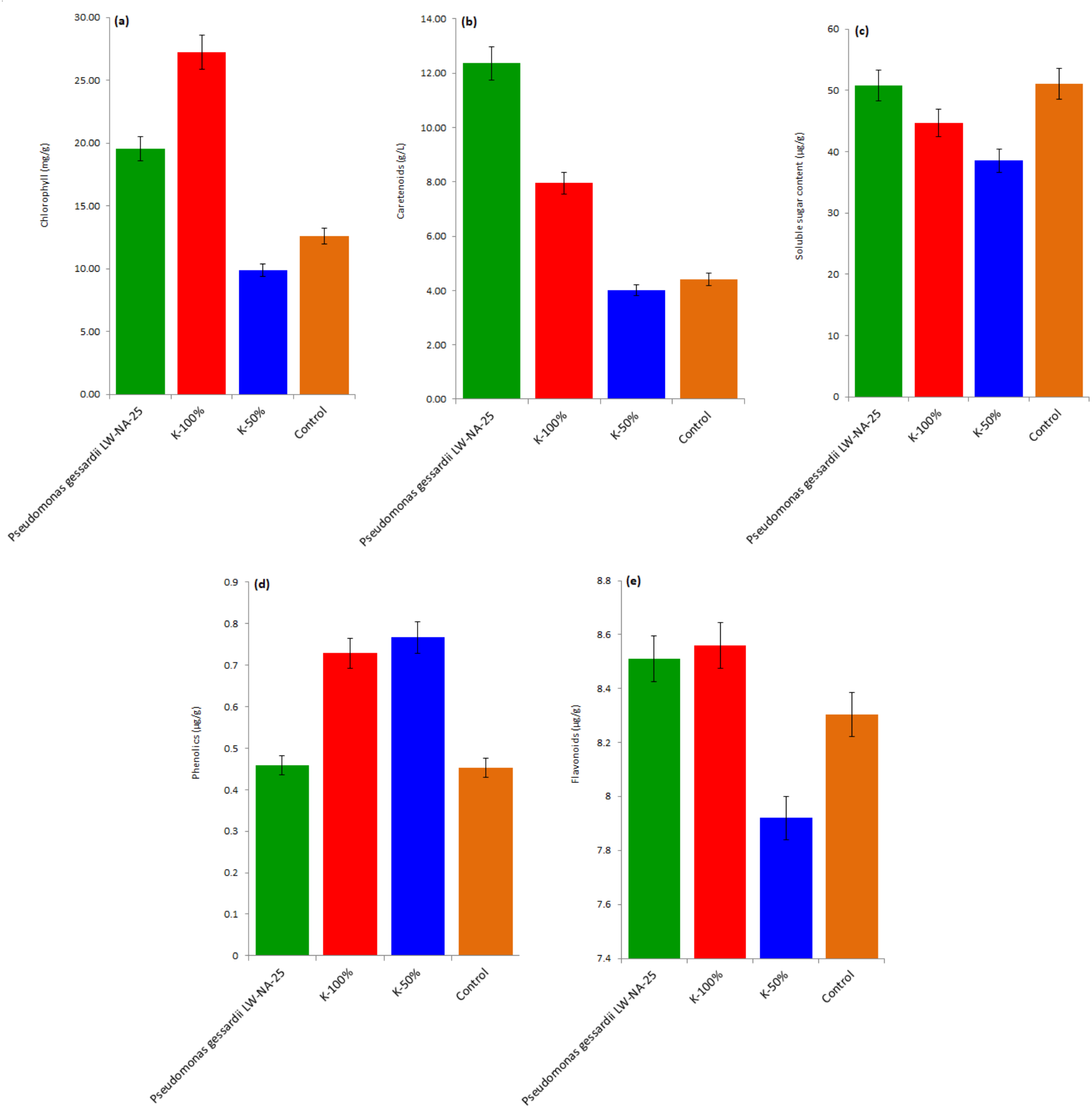

Fig. 4. The effect of potential KSB on growth of barley in term of (a) chlorophylls contents (b) carotenoids (c) total soluble sugar content (d).

The inoculation of this strain in the tobacco seedling has and plant growth (40).

been known to enhance the growth by increasing the uptake of potassium and nitrogen (36). In a similar report, Frateuria aurantia was reported as a potential solubilizer of $\mathrm{K}$ and it also promotes the tobacco plant growth after inoculation as compared to control (37). Pseudomonas azotoformans was also reported for efficient solubilizer of $\mathrm{K}$ minerals. This strain was also reported for degrading the pollution and rejuvenating land for agriculture benefits (38). In another report, three bacterial strains identified as Enterobacter sp., Pantoea ananatis and Rahnella aquatilis, were reported for solubilizing both $\mathrm{K}$ and $\mathrm{P}$ mineral via organic acid production. All these strains individually enhanced the plant growth, biomass, height, diameter, leaf area of rice seedling (39). Agrobacterium tumefaciens was recognized as a pronounced $\mathrm{K}$ mineral solubilizer. The inoculation of this strain on maize plants also enhanced nutrient assimilation
In another report, Burkholderia sp. was isolated from rhizospheric soil of Mikania micrantha was reported as efficient solubilizer of potassium (41). A strain of KSM identified as Bacillus pseudomycoides promoted the uptake of potassium in the plants of tea by increasing the availability of K-mineral in the soil treated with mica waste (42). In a similar report, bacterial strain namely, Acinetobacter pittii, Cupriavidus oxalaticus, Ochrobactrum cicero and Rhizobium pusense were reported as a potential solubilizer of $\mathrm{K}$ and its inoculation improved in paddy plant enhanced the length of shoot, fresh and dry weight and content in chlorophyll under saline conditions (43). In another report, two bacterial species belonging to genera Burkholderia i.e. B. licheniformis and B. cenocepacia were reported as efficient $\mathrm{K}$ solubilizers. The inoculation of these strains in tomato 
plants, increases its growth parameters like leaf area, both 7 root and shoot length and $\mathrm{K}$ content as well (44). Ksolubilizer with PGP ability have been exploited as agricultural agents for cereal crops under suitable inoculants for low temperature season, crops grown in regions like alpine, sub-alpine, high altitude regions and low temperature areas and used in the mitigation of K-deficient soils .

\section{Conclusion}

In conclusion, the utility of such $\mathrm{K}$ solubilizing/mobilizing strains in different agro-ecological systems is enormous when considering the unique the climatic conditions and crop growing situations of the different agricultural systems. The potential of the KSB to promote plant growth in barley requires further evaluation and validation under in vivo conditions before its use as bio-inoculants in the different agro-ecosystems. The selection of native functional PGP microbes is a required step for reducing the energy use intensive chemical fertilisers. The strain reported in this study may be considered as a future candidate for promotion as bio- inoculants, due to its multiple PGP abilities

\section{Authors contributions}

TK wrote the manuscript, DK and RD helped in analysis, AY helped in figure and table formation and ANY made the hypothesis and reviewed the manuscript.

\section{Compliance with ethical standards}

Conflict of interest: : There are no conflicts of interest.

Ethical issues: None.

\section{References}

1. Sparks D, Huang P. Physical chemistry of soil potassium. In: Munson RD (ed.), Potassium in agriculture, American Society of Agronomy, Medison. 1985; pp. 201-76. https:// doi.org/10.2134/1985.potassium.c9

2. Meena VS, Maurya B, Verma JP. Does a rhizospheric microorganism enhance $\mathrm{K}^{+}$availability in agricultural soils? Microbiol Res. 2014;169(5-6):337-47. j.micres.2013.09.003 https://doi.org/10.1016/

3. Parmar $P$, Sindhu S. Potassium solubilization by rhizosphere bacteria: influence of nutritional and environmental conditions. J Microbiol Res. 2013;3(1):25-31. https://doi.org/10.5923/ j.microbiology.20130301.04

4. Yadav AN, Kour D, Kaur T, Devi R, Yadav A, Dikilitas M, et al. Biodiversity, and biotechnological contribution of beneficial soil microbiomes for nutrient cycling, plant growth improvement and nutrient uptake. Biocatal Agric Biotechnol. 2021;33:102009. https://doi.org/10.1016/j.bcab.2021.102009

5. Archana D, Nandish M, Savalagi V, Alagawadi A. Screening of potassium solubilizing bacteria (KSB) for plant growth promotionalactivity. Bioinfolet. 2012;9(4):627-30.

6. Kaur T, Devi R, Kour D, Yadav A, Yadav AN, Dikilitas M, et al. Plant growth promoting soil microbiomes and their potential implications for agricultural and environmental sustainability. Biologia. 2021;76:2687-709. https://doi.org/10.1007/s11756-021-00806-w
Kour D, Rana KL, Yadav AN, Yadav N, Kumar M, Kumar V, et al. Microbial biofertilizers: Bioresources and eco-friendly technologies for agricultural and environmental sustainability. Biocatal Agric Biotechnol. 2020;23:101487. https://doi.org/10.1016/ j.bcab.2019.101487

8. Yadav AN, Verma P, Kumar S, Kumar V, Kumar M, Sugitha TCK, et al. Actinobacteria from rhizosphere: molecular diversity, distributions, and potential biotechnological applications. In: Singh BP., Gupta VK., Passari AK (eds), New and Future Developments in Microbial Biotechnology and Bioengineering, Elsevier. 2018; pp. 13-41. https://doi.org/10.1016/B978-0-444-63994-3.00002-3

9. Chen Y, Rekha P, Arun A, Shen F, Lai W-A, Young C. Phosphate solubilizing bacteria from subtropical soil and their tricalcium phosphate solubilizing abilities. Appl Soil Ecol. 2006;34(1):33-41. https://doi.org/10.1016/j.apsoil.2005.12.002

10. Sheng X-F, He L-Y, Huang W-Y. The conditions of releasing potassium by a silicate-dissolving bacterial strain NBT. Agric Sci China. 2002;1(6):662-6.

11. Gundala PB, Chinthala P, Sreenivasulu B. A new facultative alkaliphilic, potassium solubilizing, Bacillus sp. SVUNM9 isolated from mica cores of Nellore District, Andhra Pradesh, India. Research and Reviews. J Microbiol Biotechnol. 2013;2(1):1-7.

12. Sheng XF, He LY. Solubilization of potassium-bearing minerals by a wild-type strain of Bacillus edaphicus and its mutants and increased potassium uptake by wheat. Can J Microbiol. 2006;52 (1):66-72. https://doi.org/10.1139/W05-117

13. Archana D, Nandish M, Savalagi V, Alagawadi A. Characterization of potassium solubilizing bacteria (KSB) from rhizosphere soil. Bioinfolet. 2013;10(1b):248-57.

14. Yadav AN, Kumar V, Prasad R, Saxena AK, Dhaliwal HS. Microbiome in Crops: Diversity, distribution and potential role in crops improvements. In: Prasad R., Gill SS., Tuteja N., (eds.), Crop Improvement through Microbial Biotechnology, Elsevier, USA. 2018; pp. 305-32. https://doi.org/10.1016/B978-0-444-63987-5.00015-3

15. Yadav AN, Mishra S, Singh S, Gupta A. Recent Advancement in White Biotechnology Through Fungi Volume 1: Diversity and Enzymes Perspectives. Springer International Publishing, Cham. 2019.

16. Yadav AN, Singh S, Mishra S, Gupta A. Recent Advancement in White Biotechnology Through Fungi. Volume 2: Perspective for Value-Added Products and Environments. Springer International Publishing, Cham. 2019.

17. Vyas $P$, Gulati A. Organic acid production in vitro and plant growth promotion in maize under controlled environment by phosphate-solubilizing fluorescent Pseudomonas. BMC Microbiol. 2009;9(1):174. https://doi.org/10.1186/1471-2180-9-174

18. Lian B, Fu P, Mo D, Liu C. A comprehensive review of the mechanism of potassium releasing by silicate bacteria. Acta Mineral Sin. 2002;22(2):179-83.

19. Hu X, Chen J, Guo J. Two Phosphate- and Potassium-solubilizing Bacteria Isolated from Tianmu Mountain, Zhejiang, China. World J Microbiol Biotechnol. 2006;22(9):983-90. https:// doi.org/10.1007/s11274-006-9144-2

20. Pikovskaya R. Mobilization of phosphorus in soil in connection with vital activity of some microbial species. Mikrobiologiya. 1948;17:362-70.

21. Saravanan VS, Subramoniam SR, Raj SA. Assessing in vitro solubilization potential of different zinc solubilizing bacterial (zsb) isolates. Braz J Microbiol. 2004;35(1-2):121-5.

22. Yadav AN, Sachan SG, Verma P, Saxena AK. Bioprospecting of plant growth promoting psychrotrophic Bacilli from the cold desert of north western Indian Himalayas. Indian J Exp Biol. 2016;54:142-50. 
23. Yadav AN, Sachan SG, Verma P, Tyagi SP, Kaushik R, Saxena AK. Culturable diversity and functional annotation of psychrotrophic bacteria from cold desert of Leh Ladakh (India). World J Microbiol Biotechnol. 2015;31(1):95-108. https://doi.org/10.1007/s11274014-1768-z

24. Tamura K, Dudley J, Nei M, Kumar S. MEGA4: molecular evolutionary genetics analysis (MEGA) software version 4.0. Mol Biol Evol. 2007;24(8):1596-9. https://doi.org/10.1093/molbev/ msm092

25. Lichtenthaler HK. [34] Chlorophylls and carotenoids: Pigments of photosynthetic biomembranes. Methods Enzymol. 1987;148:350 -82. https://doi.org/10.1016/0076-6879(87)48036-1

26. Irigoyen J, Einerich D, Sánchez-Díaz M. Water stress induced changes in concentrations of proline and total soluble sugars in nodulated alfalfa (Medicago sativa) plants. Physiol Plant. 1992;84 (1):55-60. https://doi.org/10.1111/j.1399-3054.1992.tb08764.x

27. Verma P, Yadav AN, Kazy SK, Saxena AK, Suman A. Elucidating the diversity and plant growth promoting attributes of wheat (Triticum aestivum) associated acidotolerant bacteria from southern hills zone of India. Natl J Life Sci. 2013;10(2):219-27.

28. Verma P, Yadav AN, Kazy SK, Saxena AK, Suman A. Evaluating the diversity and phylogeny of plant growth promoting bacteria associated with wheat (Triticum aestivum) growing in central zone of India. Int J Curr Microbiol Appl Sci. 2014;3(5):432-47.

29. Verma P, Yadav AN, Khannam KS, Panjiar N, Kumar S, Saxena AK, et al. Assessment of genetic diversity and plant growth promoting attributes of psychrotolerant bacteria allied with wheat (Triticum aestivum) from the northern hills zone of India. Ann Microbiol. 2015;65:1885-99. https://doi.org/10.1007/s13213-0141027-4

30. Verma P, Yadav AN, Shukla L, Saxena AK, Suman A. Alleviation of cold stress in wheat seedlings by Bacillus amyloliquefaciens IARIHHS2-30, an endophytic psychrotolerant K-solubilizing bacterium from NW Indian Himalayas. Natl J Life Sci. 2015;12(2):10510.

31. Verma P, Yadav AN, Khannam KS, Kumar S, Saxena AK, Suman A. Molecular diversity and multifarious plant growth promoting attributes of Bacilli associated with wheat (Triticum aestivum L.) rhizosphere from six diverse agro-ecological zones of India. J Basic Microbiol. 2016;56(1):44-58. https://doi.org/10.1002/ jobm.201500459

32. Saleem M, Asghar HN, Zahir ZA, Shahid M. Evaluation of lead tolerant plant growth promoting rhizobacteria for plant growth and phytoremediation in lead contamination. Rev Int Contam Ambient. 2019;35(4):999-1009. https://doi.org/10.20937/ rica.2019.35.04.18

33. Heredia-Acuña C, Almaraz-Suarez JJ, Arteaga-Garibay R, FerreraCerrato R, Pineda-Mendoza DY. Isolation, characterization and effect of plant-growth-promoting rhizobacteria on pine seedlings (Pinus pseudostrobus Lindl.). J For Res. 2019;30(5):1727-34. https://doi.org/10.1007/s11676-018-0723-5

34. Sangeeth K, Bhai RS, Srinivasan V. Paenibacillus glucanolyticus, a promising potassium solubilizing bacterium isolated from black pepper (Piper nigrum L.) rhizosphere. J Spices Aromat Crops. 2012;21(2):118-24.
35. Keshavarz Zarjani J, Aliasgharzad N, Oustan S, Emadi M, Ahmadi A. Isolation and characterization of potassium solubilizing bacteria in some Iranian soils. Arch Agron Soil Sci. 2013;59(12):1713-23. https://doi.org/10.1080/03650340.2012.756977

36. Zhang C, Kong F. Isolation and identification of potassiumsolubilizing bacteria from tobacco rhizospheric soil and their effect on tobacco plants. Appl Soil Ecol. 2014;82:18-25. https:// doi.org/10.1016/j.apsoil.2014.05.002

37. Subhashini D. Growth promotion and increased potassium uptake of tobacco by potassium-mobilizing bacterium Frateuria aurantia grown at different potassium levels in vertisols. Commun Soil Sci Plant Anal. 2015;46(2):210-20. https:// doi.org/10.1080/00103624.2014.967860

38. Saha M, Maurya BR, Meena VS, Bahadur I, Kumar A. Identification and characterization of potassium solubilizing bacteria (KSB) from Indo-Gangetic Plains of India. Biocatal Agric Biotechnol. 2016;7:202-9. https://doi.org/10.1016/j.bcab.2016.06.007

39. Bakhshandeh E, Pirdashti H, Lendeh KS. Phosphate and potassium-solubilizing bacteria effect on the growth of rice. Ecol Eng. 2017;103:164-9. https://doi.org/10.1016/j.ecoleng.2017.03.008

40. Meena VS, Zaid A, Maurya BR, Meena SK, Bahadur I, Saha M, et al. Evaluation of potassium solubilizing rhizobacteria (KSR): enhancing K-bioavailability and optimizing K-fertilization of maize plants under Indo-Gangetic Plains of India. Environ Sci Pollut Resh. 2018;25(36):36412-24. https://doi.org/10.1007/s11356-0183571-0

41. Sun F, Ou Q, Wang N, Guo Zx, Ou Y, Li N, et al. Isolation and identification of potassium-solubilizing bacteria from Mikania micrantha rhizospheric soil and their effect on M. micrantha plants. Global Ecol Conserv. 2020;23:e01141. https://doi.org/10.1016/ j.apsoil.2014.05.002

42. Pramanik P, Goswami AJ, Ghosh S, Kalita C. An indigenous strain of potassium-solubilizing bacteria Bacillus pseudomycoides enhanced potassium uptake in tea plants by increasing potassium availability in the mica waste-treated soil of North-east India. J Appl Microbiol. 2019;126(1):215-22. https://doi.org/10.1111/ jam. 14130

43. Ashfaq M, Hassan HM, Ghazali AHA, Ahmad M. Halotolerant potassium solubilizing plant growth promoting rhizobacteria may improve potassium availability under saline conditions. Environ Monit Assess. 2020;192(11):697. https://doi.org/10.1007/s10661020-08655-X

44. Suyal DC, Joshi D, Kumar S, Bhatt P, Narayan A, Giri K, et al. Himalayan Microbiomes for Agro-Environmental Sustainability: Current Perspectives and Future Challenges. Microb Ecol. 2021. https://doi.org/10.1007/s00248-021-01849-x 